\title{
Increased food intake by insufficient sleep in humans: are we jumping the gun on the hormonal explanation?
}

\author{
Jean-Philippe Chaput ${ }^{1}{ }^{*}$ and Marie-Pierre St-Onge ${ }^{2}$ \\ 1 Healthy Active Living and Obesity Research Group, Children's Hospital of Eastern Ontario Research Institute, Ottawa, ON, Canada \\ ${ }^{2}$ Department of Medicine, College of Physicians and Surgeons, New York Obesity Nutrition Research Center, Columbia University, New York, NY, USA \\ ${ }^{*}$ Correspondence: jpchaput@cheo.on.ca
}

Edited by:

Sridhar R. Gumpeny, Endocrine and Diabetes Centre, India

Reviewed by:

Tamara Castañeda, German Diabetes Center, Germany

Sebastian Michael Schmid, University of Luebeck, Germany

Keywords: sleep, food intake, energy balance, obesity, hormones

Concurrent with the increase in obesity prevalence, a decrease in sleep duration has been observed over the past decades $(1,2)$. Scientists have been intrigued by this inverse trend between sleep and body weight, and studies published in the past 10 years have been helpful in determining if the lack of sleep is a possible cause of obesity (3). Epidemiologic evidence has shown that short sleep duration is associated with obesity and weight gain (4-6), while shortterm experimental studies have provided important mechanistic explanations (7-9). More recently, intervention studies have also been able to demonstrate that sleep restriction causes weight gain $(10,11)$. Collectively, the evidence suggests that insufficient sleep plays a role in the risk of gaining weight, and sleep hygiene should be considered in the prevention as well as in the treatment of obesity (12-14).

The main mechanism by which insufficient sleep may predispose to weight gain is through an increase in food intake (15). In fact, sleep restriction appears to increase 24 -h energy expenditure by $\sim 5 \%$, mainly due to the energy cost of additional wakefulness $(11,16)$. Although a decrease in physical activity energy expenditure is possible for some individuals after sleep restriction, large inter-individual variations exist, and we concluded from a recent comprehensive review of the literature that short sleep duration does not substantially affect components of energy expenditure (17). In contrast, there is strong support for the notion that restricting sleep increases food intake (18-20), suggesting that energy consumption is a key mediator of the association between insufficient sleep and weight gain.
It is well demonstrated that insufficient sleep enhances our vulnerability to overeat in the current obesogenic environment $(15,21)$. Indeed, there is accumulating and consistent evidence showing that short sleep duration, poor sleep quality, and later bedtimes are all associated with increased food intake, poor diet quality, and excess body weight (15). This field of research has been fueled by the seminal study conducted by Spiegel et al. (22) in which they experimentally tested the acute effects of sleep restriction on appetite control. Briefly, they observed that healthy young men undergoing two nights of sleep restriction with controlled energy intake via an intravenous glucose infusion had decreased leptin levels, elevated ghrelin levels, and increased self-reported ratings of hunger and appetite. However, feeding procedures not typical of real-life conditions in this controlled experiment certainly limit the external generalizability of the findings. Interestingly, experimental studies that have relied on free access to food, a scenario more representative of daily living, are generally consistent in showing that sleep restriction is not associated with changes in ghrelin or leptin levels, or even leads to an increase in leptin levels (23-28). Despite no up-regulation of appetite-stimulating hormones, ad libitum experiments are generally consistent in showing that sleep restriction increases caloric intake. Thus, excess energy intake associated with not getting enough sleep appears to be preferentially driven by hedonic rather than hormonal factors $(15,29)$.

The growing body of evidence not being able to replicate Spiegel's findings in a more natural context with regard to leptin and ghrelin levels certainly suggests that the "hormonal explanation" is perhaps not the most important mechanism to explain the link between lack of sleep and increased food intake. There are at least two important explanations to this observation. First, sleep timing (bedtime and wake up time) certainly has implications on sleep architecture and appetite hormones (3034). Early wake times in the sleep restriction condition, as in Spiegel's study, as opposed to anchoring the sleep episode on wake up time, is likely to stimulate hunger by increasing appetite hormones (probably due to the increased fasting period between wake time and the initial blood draw). Second, the nutritional state and energy balance of study participants can also contribute to explain the conflicting results with regard to leptin and ghrelin levels. While conditions of energy restriction certainly help to enhance the neuroendocrine response of appetite, ad libitum conditions, mimicking a state of positive energy balance, are sufficient to explain the absence of difference in leptin and ghrelin concentrations with sleep loss $(35,36)$.

So, if recent investigations suggest that a change in appetite hormones is not the main mechanism by which sleep restriction increases food intake, what are some potential explanations? As shown in Figure 1, many recent sleep restriction studies suggest that the hedonic aspects of food intake override hormonal factors $(11,26,28$, 37). Eating in the absence of hunger is a common phenomenon in today's environment characterized by easy access to palatable foods and food intake is proportional to the time spent awake $(4,14)$. Studies 


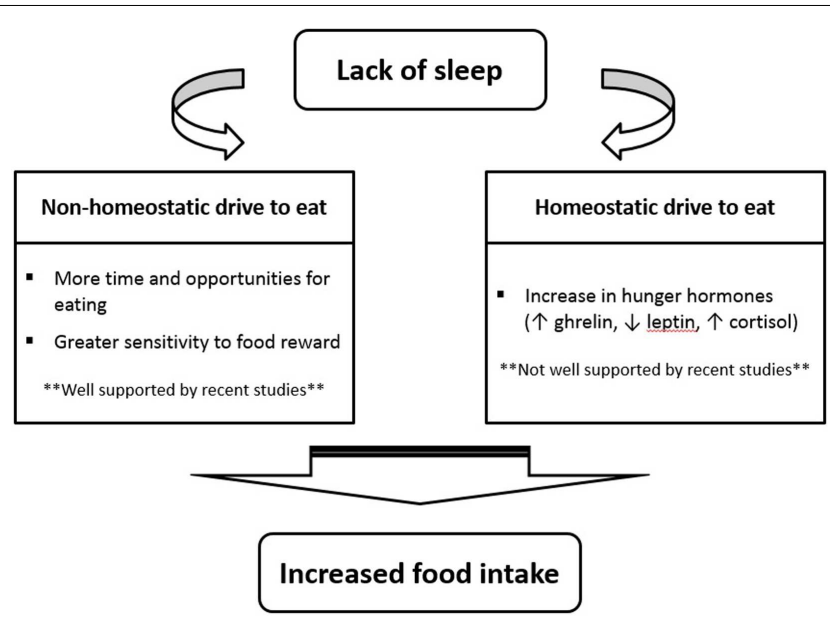

FIGURE 1 | Proposed pathways by which insufficient sleep increases caloric consumption

have consistently shown that insufficient sleep increases snacking, the number of meals eaten per day, and the preference for energy-dense food items (15). New neuroimaging experiments have also provided evidence that insufficient sleep enhances hedonic stimulus processing in the brain underlying the drive to consume foods (38-40). In particular, the insular cortex as well as areas thought to be involved in hedonic functions (e.g., orbitofrontal cortex and dorsolateral prefrontal cortex) have been found to display the strongest activation in response to unhealthy food compared to healthy food stimuli after a period of restricted sleep (40).

In conclusion, excess energy intake associated with not getting adequate sleep seems to be preferentially explained by hedonic rather than hormonal factors in the current obesogenic environment. Future studies should focus more on the rewarding aspects of food that accompany sleep loss and scientists should be more cognizant of the factors that affect hormonal measurements in the context of sleep conditions. Those factors include sex, state of energy balance (positive vs. negative), feeding status, timing of sleep and eating episodes, differences in food intake (i.e., diet quality), etc. Understanding the neuronal circuitry and central nervous system regions involved in evoking the hedonic response to food stimuli that accompanies sleep loss will be an active area of investigation in the years to come. The increased ghrelin/decreased leptin hypothesis is much too simplistic when describing the role of sleep duration in the control of food intake. Such an explanation is possibly not the key mediator, and certainly not the sole mediator, of the link between insufficient sleep and obesity.

Jean-Philippe Chaput holds a Junior Research Chair in Healthy Active Living and Obesity Research.

\section{REFERENCES}

1. Jean-Louis G, Williams NJ, Sarpong D, Pandey A, Youngstedt S, Zizi F, et al. Associations between inadequate sleep and obesity in the US adult population: analysis of the national health interview survey (1977-2009). BMC Public Health (2014) 14:290. doi:10.1186/1471-2458-14-290

2. Matricciani L, Olds T, Petkov J. In search of lost sleep: secular trends in the sleep time of schoolaged children and adolescents. Sleep Med Rev (2012) 16:203-11. doi:10.1016/j.smrv.2011.03.005

3. Chaput JP. Short sleep duration as a cause of obesity: myth or reality? Obes Rev (2011) 12:e2-3. doi:10.1111/j.1467-789X.2010.00848.x

4. Chaput JP, Tremblay A. Insufficient sleep as a contributor to weight gain: an update. Curr Obes Rep (2012) 1:245-56. doi:10.1007/s13679-012-0026-7

5. Magee L, Hale L. Longitudinal associations between sleep duration and subsequent weight gain: a systematic review. Sleep Med Rev (2012) 16:231-41. doi:10.1016/j.smrv.2011.05.005

6. Cappuccio FP, Taggart FM, Kandala NB, Currie A, Peile E, Stranges S, et al. Meta-analysis of short sleep duration and obesity in children and adults. Sleep (2008) 31:619-26.

7. Schmid SM, Hallschmid M, Schultes B. The metabolic burden of sleep loss. Lancet Diabetes Endocrinol (2014). doi:10.1016/S2213-8587(14) 70012-9

\section{ACKNOWLEDGMENTS}

8. Leproult R, Van Cauter E. Role of sleep and sleep loss in hormonal release and metabolism. Endocr Dev (2010) 17:11-21. doi:10.1159/000262524

9. Spiegel K, Tasali E, Leproult R, Van Cauter E. Effects of poor and short sleep on glucose metabolism and obesity risk. Nat Rev Endocrinol (2009) 5:253-61. doi: $10.1038 /$ nrendo.2009.23

10. Spaeth AM, Dinges DF, Goel N. Effects of experimental sleep restriction on weight gain, caloric intake, and meal timing in healthy adults. Sleep (2013) 36:981-90.

11. Markwald RR, Melanson EL, Smith MR, Higgins J, Perreault L, Eckel RH, et al. Impact of insufficient sleep on total daily energy expenditure, food intake, and weight gain. Proc Natl Acad Sci U S A (2013) 110:5695-700. doi:10.1073/pnas. 1216951110

12. Hart CN, Carskadon MA, Considine RV, Fava JL, Lawton J, Raynor HA, et al. Changes in children's sleep duration on food intake, weight, and leptin. Pediatrics (2013) 132:e1473-80. doi:10.1542/peds. 2013-1274

13. Haines J, McDonald J, O’Brien A, Sherry B, Bottino CJ, Schmidt ME, et al. Healthy habits, happy homes: randomized trial to improve household routines for obesity prevention among preschoolaged children. JAMA Pediatr (2013) 167:1072-9. doi:10.1001/jamapediatrics.2013.2356

14. Chaput JP, Tremblay A. Adequate sleep to improve the treatment of obesity. CMAJ (2012) 184:1975-6. doi:10.1503/cmaj.120876

15. Chaput JP. Sleep patterns, diet quality and energy balance. Physiol Behav (2014). doi:10.1016/ j.physbeh.2013.09.006

16. Shechter A, Rising R, Albu JB, St-Onge MP. Experimental sleep curtailment causes wake-dependent increases in 24-h energy expenditure as measured by whole-room indirect calorimetry. Am J Clin Nutr (2013) 98:1433-9. doi:10.3945/ajcn.113. 069427

17. Klingenberg L, Sjödin A, Holmbäck U, Astrup A, Chaput JP. Short sleep duration and its association with energy metabolism. Obes Rev (2012) 13:565-77. doi:10.1111/j.1467-789X.2012.00991.x

18. St-Onge MP. The role of sleep duration in the regulation of energy balance: effects on energy intakes and expenditure. J Clin Sleep Med (2013) 9:73-80. doi: $10.5664 /$ jcsm. 2348

19. Chapman CD, Benedict C, Brooks SJ, Schiöth HB. Lifestyle determinants of the drive to eat: a meta-analysis. Am J Clin Nutr (2012) 96:492-7. doi:10.3945/ajen.112.039750

20. Chaput JP, Klingenberg L, Sjödin A. Do all sedentary activities lead to weight gain: sleep does not. Curr Opin Clin Nutr Metab Care (2010) 13:601-7. doi:10.1097/MCO.0b013e32833ef30e

21. Chaput JP, Klingenberg L, Astrup A, Sjödin AM. Modern sedentary activities promote overconsumption of food in our current obesogenic environment. Obes Rev (2011) 12:12-20. doi:10.1111/ j.1467-789X.2010.00772.x

22. Spiegel K, Tasali E, Penev P, Van Cauter E. Brief communication: sleep curtailment in healthy young men is associated with decreased leptin levels, elevated ghrelin levels, and increased hunger and appetite. Ann Intern Med (2004) 141:846-50. doi:10.7326/0003-4819-14111-200412070-00008

23. Simpson NS, Banks S, Dinges DF. Sleep restriction is associated with increased morning plasma 
leptin concentrations, especially in women. Biol Res Nurs (2010) 12:47-53. doi:10.1177/ 1099800410366301

24. Pejovic S, Vgontzas AN, Basta M, Tsaoussoglou M, Zoumakis E, Vgontzas A, et al. Leptin and hunger levels in young healthy adults after one night of sleep loss. J Sleep Res (2010) 19:552-8. doi:10.1111/j.1365-2869.2010.00844.x

25. Omisade A, Buxton OM, Rusak B. Impact of acute sleep restriction on cortisol and leptin levels in young women. Physiol Behav (2010) 99:651-6. doi:10.1016/j.physbeh.2010.01.028

26. Nedeltcheva AV, Kilkus JM, Imperial J, Kasza K, Schoeller DA, Penev PD. Sleep curtailment is accompanied by increased intake of calories from snacks. Am J Clin Nutr (2009) 89:126-33. doi:10. 3945/ajcn.2008.26574

27. Schmid SM, Hallschmid M, Jauch-Chara K, Wilms B, Benedict C, Lehnert H, et al. Short-term sleep loss decreases physical activity under free-living conditions but does not increase food intake under time-deprived laboratory conditions in healthy men. Am J Clin Nutr (2009) 90:1476-82. doi:10. 3945/ajcn.2009.27984

28. Bosy-Westphal A, Hinrichs S, Jauch-Chara K, Hitze B, Later W, Wilms B, et al. Influence of partial sleep deprivation on energy balance and insulin sensitivity in healthy women. Obes Facts (2008) 1:266-73. doi: $10.1159 / 000158874$

29. St-Onge MP. The role of sleep in the control of feeding behavior. In: Watson R, editor. Modulation of Sleep by Obesity, Diabetes, Age, and Diet. Elsevier (2014).

30. Gonnissen HK, Hulshof T, Westerterp-Plantenga MS. Chronobiology, endocrinology, and energy- and food-reward homeostasis. Obes Rev (2013) 14:405-16. doi:10.1111/obr.12019

31. Baron KG, Reid KJ, Kern AS, Zee PC. Role of sleep timing in caloric intake and BMI. Obesity (Silver Spring) (2011) 19:1374-81. doi:10.1038/oby.2011. 100

32. Johnston JD, Frost G, Otway DT. Adipose tissue, adipocytes and the circadian timing system. Obes Rev (2009) 10(Suppl 2):52-60. doi:10.1111/j. 1467-789X.2009.00665.x

33. Rüger M, Scheer FA. Effects of circadian disruption on the cardiometabolic system. Rev Endocr Metab Disord (2009) 10:245-60. doi:10.1007/ s11154-009-9122-8

34. Arble DM, Bass J, Laposky AD, Vitaterna $\mathrm{MH}$, Turek FW. Circadian timing of food intake contributes to weight gain. Obesity (Silver Spring) (2009) 17:2100-2. doi:10.1038/oby.2009.264

35. Penev PD. Update on energy homeostasis and insufficient sleep. J Clin Endocrinol Metab (2012) 97:1792-801. doi:10.1210/jc.2012-1067

36. Chaput JP, Klingenberg L, Sjödin AM. Sleep restriction and appetite control: waking to a problem? Am J Clin Nutr (2010) 91:822-3. doi:10.3945/ajcn. 2009.29011

37. Calvin AD, Carter RE, Adachi T, Macedo PG, Albuquerque FN, van der Walt C, et al. Effects of experimental sleep restriction on caloric intake and activity energy expenditure. Chest (2013) 144:79-86. doi:10.1378/chest.12-2829

38. Benedict C, Brooks SJ, O’Daly OG, Almèn MS, Morell A, Åberg K, et al. Acute sleep deprivation enhances the brain's response to hedonic food stimuli: an fMRI study. J Clin Endocrinol Metab (2012) 97:E443-7. doi:10.1210/jc.2011-2759
39. St-Onge MP, McReynolds A, Trivedi ZB, Roberts AL, Sy M, Hirsch J. Sleep restriction leads to increased activation of brain regions sensitive to food stimuli. Am J Clin Nutr (2012) 95:818-24. doi:10.3945/ajcn.111.027383

40. St-Onge MP, Wolfe S, Sy M, Shechter A, Hirsch J. Sleep restriction increases the neuronal response to unhealthy food in normal-weight individuals Int J Obes (Lond) (2014) 38:411-6. doi:10.1038/ijo. 2013.114

Conflict of Interest Statement: The authors declare that the research was conducted in the absence of any commercial or financial relationships that could be construed as a potential conflict of interest.

Received: 12 May 2014; accepted: 02 July 2014; published online: 15 July 2014.

Citation: Chaput J-P and St-Onge M-P (2014) Increased food intake by insufficient sleep in humans: are we jumping the gun on the hormonal explanation? Front. Endocrinol. 5:116. doi: 10.3389/fendo.2014.00116 This article was submitted to Systems and Translational Endocrinology, a section of the journal Frontiers in Endocrinology.

Copyright (c) 2014 Chaput and St-Onge. This is an openaccess article distributed under the terms of the Creative Commons Attribution License (CC BY). The use, distribution or reproduction in other forums is permitted, provided the original author(s) or licensor are credited and that the original publication in this journal is cited, in accordance with accepted academic practice. No use, distribution or reproduction is permitted which does not comply with these terms. 